\title{
Increased Frequency of HLA A2/DR4 and A2/DR8 Haplotypes in Young Saskatchewan Aboriginal People with Diabetic End-Stage Renal Disease
}

\author{
Roland Dyck Clara Bohm Helena Klomp \\ Division of Nephrology, Department of Medicine, University of Saskatchewan, Saskatoon, Canada
}

\section{Key Words}

HLA - Type 2 diabetes mellitus · Aboriginal - End-stage

renal disease · Diabetic nephropathy · A2 - DR4 · DR8
DR8. Conclusions: Our findings suggest that DESRD in young $A B$ subjects with T2DM has a genetic basis related to HLA.

Copyright $@ 2003$ S. Karger AG, Basel

\begin{abstract}
Aims: To determine the association of HLA with diabetic end-stage renal disease (DESRD) in Saskatchewan aboriginal people. Methods: This was a retrospective study of HLA profiles in four groups of Saskatchewan residents with ESRD diagnosed from 1980 to 1998: aboriginal people with and without DESRD, and non-aboriginal people with and without DESRD. The aboriginal DESRD group was also subdivided into those $\leq 50$ and $>50$ years of age. Frequencies of individual and combinations of HLA antigens were compared between groups and subgroups. Results: HLA data were available for 634 subjects. Young aboriginal people with DESRD had a higher frequency of HLA-A2 than older AB DESRD subjects (69 vs. $36 \% ; p=0.03$ ), and of HLA-DR4 and/or DR8 compared to older $A B$ DESRD subjects ( 91 vs. $68 \% ; p=0.07$ ) and $A B$ non-DESRD subjects (91 vs. $67 \% ; p=0.03$ ). Over $65 \%$ of young $A B$ DESRD subjects had either an A2/DR4 or A2/ DR8 haplotype lodds ratio 5.09 [confidence intervals $1.35,20.15]$ versus older $A B$ DESRD subjects; odds ratio 3.32 [confidence intervals 1.20, 9.3] versus $A B$ nonDESRD subjects). Forty percent of young AB DESRD subjects were homozygous for at least one of A2, DR4 or
\end{abstract}

\section{KARGER}

Fax +41613061234

E-Mail karger@karger.ch

www.karger.com
(C) 2003 S. Karger AG, Basel

0250-8095/03/0233-0178\$19.50/0

Accessible online at:

www. karger.com/ajn

\section{Introduction}

Canadian aboriginal people are experiencing an epidemic of diabetic end-stage renal disease (DESRD) [1] that cannot be wholly explained by increased rates of type 2 diabetes mellitus (T2DM) [2]. After adjusting for differences in rates of diabetes, for example, we found that Saskatchewan aboriginal people with diabetes were seven times more likely to develop DESRD than their non-aboriginal diabetic counterparts [3]. Reasons for the excessive burden of DESRD in this population likely relate to both environmental and genetic factors [4]. The former may include the intrauterine milieu, delayed diagnosis of T2DM, and poorer control of hypertension and hyperglycemia. A genetic contribution to T2DM nephropathy has long been suspected because of familial clustering of cases in populations with high rates of T2DM [5-8].

While the major histocompatibility complex has elicited great interest with respect to its possible role in the genetics of diabetes, a clear association between specific HLA antigens (particularly the class II antigens DR3 and DR4) has only been recognized in type 1 diabetes mellitus
Roland F. Dyck, MD

Department of Medicine, Royal University Hospital

103 Hospital Drive

Saskatoon S7N 0W8 (Canada)

Tel. +1 306966 7985, Fax +1 306966 7996, E-Mail dyck@sask.usask.ca 
(T1DM) [9]. No similar association has been observed with consistency in populations with high rates of T2DM although an association between T2DM and HLA-A2 (a class I antigen) has been reported in Pima Indians [10]. In reviewing HLA data in the context of our renal transplant program over several years, it also appeared that certain HLA antigens might be increased among aboriginal people with DESRD caused by T2DM.

In view of the above, the purpose of this study was to determine if specific HLA antigens or combinations of antigens are associated with the presence of DESRD in Saskatchewan aboriginal people. A relationship between specific HLA antigens and DESRD in Canadian aboriginal people could contribute to an understanding of the pathogenesis of this devastating disorder, and provide possible opportunities for prevention, and early recognition and treatment of diabetic nephropathy. In addition, we considered it important to identify HLA profiles that might be associated with a higher risk of T2DM and diabetic nephropathy in potential kidney donors from aboriginal populations.

\section{Methods}

This was a retrospective study of Saskatchewan patients with end-stage renal disease (ESRD) diagnosed between January 1, 1980 and December 31, 1998. Serologically determined HLA data obtained from dialysis and transplant records maintained by the Saskatchewan Transplant Program, were linked with serial data submitted annually to the Canadian Organ Replacement Register (CORR). Parameters subsequently retrieved from CORR included a subject identifier, birth date, gender, ethnicity, cause of ESRD, and date and nature of first treatment of ESRD. For this study, ESRD was defined as the date when long-term treatment with dialysis was started, or a first transplant was carried out in an individual not yet on dialysis.

A person was considered to have DESRD if that was the diagnosis submitted to the register by the attending nephrologist. For the purpose of this study, we did not differentiate between T1DM and T2DM because T1DM is very unusual in aboriginal people, and because many diabetic non-aboriginal people had been incorrectly classified with respect to type. All patients with ESRD diagnoses other than DESRD were classified as having non-DESRD. Ethnic designation was that reported to CORR. The ethnic categories used in this study were 'aboriginal' (North American Indian, Inuit and Metis) and 'non-aboriginal' (ethnicity other than aboriginal). Over $90 \%$ of non-aboriginal subjects were Caucasian.

\section{Analysis}

Analyses were performed using SPSS (10.05) Microsoft (2000) and Epi-Info (6.02). Although our primary focus was on aboriginal people with ESRD, we were also interested in HLA profiles of nonaboriginal subjects with ESRD as a means of validating our data (non-aboriginal subjects with DESRD were expected to have higher frequencies of diabetes-related HLA antigens than non-aboriginal subjects with non-DESRD because many of the former had T1DM). Subjects were therefore initially divided into 4 main groups: (1) aboriginal (AB) people with DESRD; (2) AB people with non-DESRD; (3) non-AB people with DESRD; (4) non-AB people with nonDESRD.

For our final analyses, the AB DESRD group was subdivided into those $\leq 50$ years and those $>50$ years at the time of ESRD diagnosis. We then compared the younger AB DESRD group (cases) with two control groups (older AB DESRD subjects and all AB non-DESRD subjects). Similar to the rationale used in studying the relationship between HLA and T2DM in the Pima [10], we speculated that an association between HLA and DESRD in the AB population should decrease with age among those with DESRD, and should be lowest in those with non-DESRD. Although somewhat arbitrary, we chose age 50 to subdivide the AB DESRD group because it seemed a biologically valid age to separate younger from older subjects with DESRD, and it provided us with subgroups of similar size for analysis. We did not subdivide the $\mathrm{AB}$ non-DESRD control group because only 6 subjects in that group were older than 50 years, and because the results of our analyses were the same regardless of whether we used the total $\mathrm{AB}$ non-DESRD group or just those $\leq 50$ years as controls.

A basic descriptive analysis of the parameters listed above was carried out on all 4 groups. We looked for differences in these variables between subjects with and without HLA typing to detect possible selection bias in both ethnic groups. DESRD and non-DESRD subjects with HLA typing were then examined for comparability within each ethnic group.

Univariate analyses were used to determine the frequency of individual and combinations of HLA antigens. Bivariate variables were compared between groups with $\chi^{2}$ tests (Yates corrected) or Fisher's exact test. Comparisons of continuous variables were carried out using independent samples mean $t$ tests. The level of significance was set at $\mathrm{p} \leq 0.05$ (two-tailed). The association of HLA antigens and HLA antigen combinations with the different ESRD groups was measured by the odds ratio (OR) with corresponding $95 \%$ confidence intervals $(\mathrm{CI}) \cdot \chi^{2}$ for linear trend was used to compare HLA antigen allele, phenotype and homozygous frequencies between AB DESRD subjects $\leq 50$ years, $\mathrm{AB}$ DESRD subjects $>50$ years and $\mathrm{AB}$ nonDESRD subjects. As above, an association between HLA and DESRD was considered to be most likely in the younger AB DESRD subjects and least likely in the AB non-DESRD group. For the purpose of calculating allele frequencies [10], it was assumed that HLA antigens were homozygous when only one HLA-A, B or DR antigen was detected in a subject.

\section{Results}

Over the 18-year study period, ESRD was diagnosed in 1,684 Saskatchewan residents. Of those, 1,011 had not been HLA typed and 39 had missing diagnostic and/or ethnic designation. This left a final study sample of 634 (38\%) subjects of whom 110 were $\mathrm{AB}$ and 524 were nonAB. DESRD was diagnosed in 57 (52\%) AB people and $136(26 \%)$ non-AB people. These latter proportions were similar to those for the total ESRD population. 
Table 1. Frequency of HLA antigens by group

\begin{tabular}{|c|c|c|c|c|c|c|c|c|}
\hline \multirow[t]{3}{*}{ HLA } & \multicolumn{4}{|c|}{$\mathrm{AB}$} & \multicolumn{4}{|c|}{ Non-AB } \\
\hline & \multicolumn{2}{|c|}{ DESRD } & \multicolumn{2}{|c|}{ non-DESRD } & \multicolumn{2}{|c|}{ DESRD } & \multicolumn{2}{|c|}{ non-DESRD } \\
\hline & $\%$ & $\mathrm{n}$ & $\%$ & $\mathrm{n}$ & $\%$ & $\mathrm{n}$ & $\%$ & $\mathrm{n}$ \\
\hline Subjects with A, B & & 57 & & 53 & & 136 & & 388 \\
\hline $\mathrm{A} 1$ & 14 & 8 & 9 & 5 & 42 & 57 & 27 & $103^{c}$ \\
\hline $\mathrm{A} 2$ & 54 & 31 & 59 & 31 & 51 & 69 & 50 & 192 \\
\hline A3 & 7 & 4 & 8 & 4 & 16 & 22 & 29 & $114^{b}$ \\
\hline A9 (including A24) & 46 & 26 & 47 & 25 & 25 & 34 & 17 & 66 \\
\hline A24(9) & 42 & 24 & 34 & 18 & 15 & 21 & 13 & 52 \\
\hline A11 & 5 & 3 & 4 & 2 & 7 & 9 & 11 & 41 \\
\hline A30 & 7 & 4 & 9 & 5 & 11 & 15 & 6 & 25 \\
\hline A31 & 18 & 10 & 26 & 14 & 2 & 3 & 4 & 16 \\
\hline B5 (including B51) & 30 & 17 & 43 & 23 & 15 & 20 & 12 & 48 \\
\hline B51(5) & 28 & 16 & 32 & 17 & 7 & 10 & 10 & 39 \\
\hline B7 & 7 & 4 & 13 & 7 & 8 & 11 & 24 & $92^{\mathrm{d}}$ \\
\hline B8 & 11 & 6 & 8 & 4 & 44 & 60 & 20 & $77^{\mathrm{d}}$ \\
\hline $\mathrm{B} 18$ & 5 & 3 & 9 & 5 & 13 & 18 & 11 & 42 \\
\hline B27 & 18 & 10 & 9 & 5 & 18 & 24 & 9 & $35^{\mathrm{a}}$ \\
\hline B35 & 21 & 12 & 25 & 13 & 9 & 12 & 19 & 73 \\
\hline B39 & 12 & 7 & 13 & 7 & 4 & 5 & 3 & 13 \\
\hline B44 & 9 & 5 & 8 & 4 & 14 & 19 & 19 & 75 \\
\hline $\mathrm{B} 60$ & 11 & 6 & 4 & 2 & 9 & 12 & 8 & 29 \\
\hline B62(15) & 25 & 14 & 21 & 11 & 16 & 22 & 15 & 58 \\
\hline Subjects with DR & & 54 & & 52 & & 124 & & 365 \\
\hline DR1 & 9 & 5 & 14 & 7 & 17 & 21 & 14 & 52 \\
\hline DR2 (including DR15) & 7 & 4 & 10 & 5 & 11 & 14 & 31 & $112^{\mathrm{d}}$ \\
\hline DR15(2) & 2 & 1 & 4 & 2 & 2 & 3 & 13 & $47^{b}$ \\
\hline DR3 & 7 & 4 & 14 & 7 & 50 & 61 & 21 & $75^{\mathrm{d}}$ \\
\hline DR4 & 56 & 30 & 60 & 31 & 54 & 67 & 31 & $112^{\mathrm{d}}$ \\
\hline DR6 & 22 & 12 & 19 & 10 & 11 & 14 & 11 & 40 \\
\hline DR7 & 7 & 4 & 4 & 2 & 13 & 16 & 23 & $82^{\mathrm{a}}$ \\
\hline DR8 & 30 & 16 & 15 & 8 & 2 & 2 & 5 & 19 \\
\hline DR9 & 7 & 4 & 17 & 9 & 2 & 3 & 3 & 9 \\
\hline Subjects with DQ & & 37 & & 27 & & 66 & & 208 \\
\hline DQ1 (including DQ6) & 22 & 8 & 26 & 7 & 30 & 20 & 54 & $112^{\mathrm{c}}$ \\
\hline DQ6(1) & 5 & 2 & 4 & 1 & 3 & 2 & 11 & 22 \\
\hline DQ2 & 8 & 3 & 11 & 3 & 52 & 34 & 31 & $65^{\mathrm{b}}$ \\
\hline DQ3 (including DQ7, 8) & 78 & 29 & 89 & 24 & 68 & 45 & 65 & 135 \\
\hline DQ7 & 43 & 16 & 41 & 11 & 15 & 10 & 39 & $80^{\mathrm{c}}$ \\
\hline DQ8 & 8 & 3 & 15 & 4 & 2 & 1 & 3 & 6 \\
\hline DQ4 & 19 & 7 & 7 & 2 & 2 & 1 & 1 & 3 \\
\hline
\end{tabular}

$\chi^{2}$ comparisons between $\mathrm{AB}$ DESRD and AB non-DESRD (there were no significant differences between the AB DESRD and $\mathrm{AB}$ non-DESRD groups); non-AB DESRD and nonAB non-DESRD.

${ }^{\mathrm{a}} \mathrm{p}<0.05 ;{ }^{\mathrm{b}} \mathrm{p} \leq 0.01 ;{ }^{\mathrm{c}} \mathrm{p} \leq 0.001 ;{ }^{\mathrm{d}} \mathrm{p} \leq 0.0001$.
With respect to ethnicity, there were no significant differences in the proportion of $\mathrm{AB}$ and non- $\mathrm{AB}$ subjects who were tissue typed. There were also no differences in gender within and between groups. Among both $\mathrm{AB}$ and non-AB people, however, HLA-typed subjects were signif- icantly younger when first treated for ESRD than those not tissue typed. (For AB subjects mean age 40.5 years versus 57.5 years respectively; $p<0.001$. For non-AB subjects, mean age 42.5 years versus 65.7 years respectively; $\mathrm{p}<0.001$.) AB non-DESRD subjects were more likely to 
Table 2. Frequency of selected HLA antigens by aboriginal group

\begin{tabular}{|c|c|c|c|c|c|c|c|c|}
\hline \multirow[t]{3}{*}{ HLA } & \multicolumn{6}{|c|}{ AB DESRD } & \multirow{2}{*}{\multicolumn{2}{|c|}{$\begin{array}{l}\text { AB non- } \\
\text { DESRD }\end{array}$}} \\
\hline & \multicolumn{2}{|l|}{ all } & \multicolumn{2}{|c|}{$\leq 50$} & \multicolumn{2}{|c|}{$>50$} & & \\
\hline & $\%$ & $\mathrm{n}$ & $\%$ & $\mathrm{n}$ & $\%$ & $\mathrm{n}$ & $\%$ & $\mathrm{n}$ \\
\hline Subjects with A, B & & 57 & & 32 & & 25 & & 53 \\
\hline A1 & 14 & 8 & 6 & 2 & 24 & 6 & 9 & 5 \\
\hline $\mathrm{A} 2$ & 54 & 31 & 69 & 22 & 36 & $9^{a}$ & 59 & 31 \\
\hline A9 (including A24) & 46 & 26 & 44 & 14 & 48 & 12 & 47 & 25 \\
\hline A24(9) & 42 & 24 & 38 & 12 & 48 & 12 & 34 & 18 \\
\hline A31 & 18 & 10 & 13 & 4 & 24 & 6 & 26 & 14 \\
\hline $\mathrm{B} 27$ & 18 & 10 & 16 & 5 & 20 & 5 & 9 & 5 \\
\hline B35 & 21 & 12 & 22 & 7 & 20 & 5 & 25 & 13 \\
\hline B39 & 12 & 7 & 19 & 6 & 4 & 1 & 13 & 7 \\
\hline B44 & 9 & 5 & 16 & 5 & 0 & 0 & 8 & 4 \\
\hline B5 (including B51) & 30 & 17 & 28 & 9 & 32 & 8 & 43 & 23 \\
\hline B51(5) & 28 & 16 & 28 & 9 & 28 & 7 & 32 & 17 \\
\hline $\mathrm{B} 60$ & 11 & 6 & 16 & 5 & 4 & 1 & 4 & 2 \\
\hline B62(15) & 25 & 14 & 19 & 6 & 32 & 8 & 21 & 11 \\
\hline Subjects with DR & & 54 & & 32 & & 22 & & 52 \\
\hline DR3 & 7 & 4 & 6 & 2 & 9 & 2 & 14 & 7 \\
\hline DR4 & 56 & 30 & 59 & 19 & 50 & 11 & 60 & 31 \\
\hline DR6 & 22 & 12 & 13 & 4 & 36 & 8 & 19 & 10 \\
\hline DR8 & 30 & 16 & 32 & 10 & 27 & 6 & 15 & 8 \\
\hline DR4 and/or DR8 & 81 & 44 & 91 & 29 & 68 & $15^{\mathrm{b}}$ & 67 & $35^{\mathrm{a}}$ \\
\hline Subjects with DQ & & 37 & & 24 & & 13 & & 27 \\
\hline DQ1 (including DQ6) & 22 & 8 & 21 & 5 & 23 & 3 & 26 & 7 \\
\hline $\mathrm{DQ}(6)$ & 5 & 2 & 4 & 1 & 8 & 1 & 4 & 1 \\
\hline DQ3 (including DQ7, 8) & 78 & 29 & 83 & 20 & 69 & 9 & 89 & 24 \\
\hline DQ7 & 43 & 16 & 44 & 10 & 46 & 6 & 41 & 11 \\
\hline DQ8 & 8 & 3 & 8 & 2 & 8 & 1 & 15 & 4 \\
\hline DQ4 & 19 & 7 & 21 & 5 & 15 & 2 & 7 & 2 \\
\hline
\end{tabular}

$\chi^{2}$ comparisons between AB-DESRD $\leq 50$ and AB DESRD $>50 ; \mathrm{AB}$ DESRD $\leq 50$ and $\mathrm{AB}$ non-DESRD.

${ }^{\mathrm{a}} \mathrm{p}=0.03 ;{ }^{\mathrm{b}} \mathrm{p}=0.07$ have been tissue typed than AB DESRD subjects ( $\mathrm{p}<$ 0.001); however, $\mathrm{AB}$ non-DESRD subjects were much younger than those with DESRD.

Table 1 shows the frequency of HLA antigens that were present in at least $10 \%$ of subjects within any one of our four main study groups. The most common HLA antigens among $\mathrm{AB}$ subjects were $\mathrm{A} 2, \mathrm{~A} 9$ (including $\mathrm{A} 24$ ) and A31; B5 (including B51), B27, B35, and B62; DR4, DR6 and DR8; and DQ1 (including DQ6), DQ3 (including DQ7 and 8) and DQ4. There was a somewhat higher frequency of the A24, B27, DR8 and DQ4 antigens in AB DESRD subjects; and of the A31 antigen in AB nonDESRD subjects. None of the differences, however, were statistically significant.

HLA Profiles in Canadian Aborigina

People with Severe Diabetic Nephropathy
The most common HLA antigens in the non- $A B$ groups were A1, A2, A3 and A9 (including A24); B7, B8, B27 and B35; DR2 (including DR15), DR3, DR4 and DR7; and DQ1 (including DQ6), DQ2, and DQ3 (including DQ7 and 8). Those with DESRD had significantly higher frequencies of the HLA antigens A1, B8, B27, DR3, DR4, and DQ2. The HLA antigens A3, B7, DR2 (including DR15), DR7, DQ1 and DQ7 (but not DQ3) were present in significantly higher frequencies in non-AB subjects with non-DESRD.

Table 2 shows the most common HLA antigens in $\mathrm{AB}$ subjects. AB DESRD subjects $\leq 50$ years had a significantly higher frequency of the $\mathrm{A} 2$ antigen compared to $\mathrm{AB}$ DESRD subjects $>50$ years of age (69 vs. $36 \% ; p=0.03$ ), and also had higher frequencies of the DR4, DR8, DQ3

Am J Nephrol 2003;23:178-185 181 
Table 3. Frequencies of selected HLA antigens in aboriginal people with renal failure

\begin{tabular}{|c|c|c|c|c|c|c|c|c|}
\hline Antigen & Group & $\begin{array}{l}\text { Homo- } \\
\text { zygous }\end{array}$ & $\begin{array}{l}\text { Hetero- } \\
\text { zygous }\end{array}$ & $\begin{array}{l}\text { No } \\
\text { allele }\end{array}$ & $\begin{array}{l}\text { Total } \\
\text { subjects }\end{array}$ & $\begin{array}{l}\text { Allele } \\
\text { frequency }\end{array}$ & $\begin{array}{l}\text { Phenotype } \\
\text { frequency }\end{array}$ & $\begin{array}{l}\text { Homozygous } \\
\text { frequency }\end{array}$ \\
\hline $\mathrm{A} 2$ & $\begin{array}{l}\text { DESRD } \leq 50 \\
\text { DESRD }>50 \\
\text { Non-DESRD } \\
\chi^{2} \text { linear trend }\end{array}$ & $\begin{array}{l}7 \\
1 \\
6\end{array}$ & $\begin{array}{r}15 \\
8 \\
25\end{array}$ & $\begin{array}{l}10 \\
16 \\
22\end{array}$ & $\begin{array}{l}32 \\
25 \\
53\end{array}$ & $\begin{array}{l}0.45 \\
0.20 \\
0.35 \\
p=0.005\end{array}$ & $\begin{array}{l}0.69 \\
0.36 \\
0.59 \\
p=0.01\end{array}$ & $\begin{array}{l}0.22 \\
0.04 \\
0.11 \\
p=0.04\end{array}$ \\
\hline DR4 & $\begin{array}{l}\text { DESRD } \leq 50 \\
\text { DESRD }>50 \\
\text { Non-DESRD } \\
\chi^{2} \text { linear trend }\end{array}$ & $\begin{array}{l}8 \\
2 \\
9\end{array}$ & $\begin{array}{r}11 \\
9 \\
22\end{array}$ & $\begin{array}{l}13 \\
11 \\
21\end{array}$ & $\begin{array}{l}32 \\
22 \\
52\end{array}$ & $\begin{array}{l}0.42 \\
0.30 \\
0.39 \\
\text { n.s. }\end{array}$ & $\begin{array}{l}0.59 \\
0.50 \\
0.60 \\
\text { n.s. }\end{array}$ & $\begin{array}{l}0.25 \\
0.09 \\
0.17 \\
\text { n.s. }\end{array}$ \\
\hline DR8 & $\begin{array}{l}\text { DESRD } \leq 50 \\
\text { DESRD }>50 \\
\text { Non-DESRD } \\
\chi^{2} \text { linear trend }\end{array}$ & $\begin{array}{l}3 \\
1 \\
1\end{array}$ & $\begin{array}{l}7 \\
5 \\
7\end{array}$ & $\begin{array}{l}22 \\
16 \\
44\end{array}$ & $\begin{array}{l}32 \\
22 \\
52\end{array}$ & $\begin{array}{l}0.20 \\
0.16 \\
0.09 \\
p=0.03\end{array}$ & $\begin{array}{l}0.31 \\
0.27 \\
0.15 \\
\text { n.s. }\end{array}$ & $\begin{array}{l}0.09 \\
0.05 \\
0.02 \\
\text { n.s. }\end{array}$ \\
\hline $\begin{array}{l}\text { DR4 } \\
\text { and/or } \\
\text { DR8 }\end{array}$ & $\begin{array}{l}\text { DESRD } \leq 50 \\
\text { DESRD }>50 \\
\text { Non-DESRD } \\
\chi^{2} \text { linear trend }\end{array}$ & $\begin{array}{r}11 \\
3 \\
10\end{array}$ & $\begin{array}{l}18 \\
12 \\
25\end{array}$ & $\begin{array}{r}3 \\
7 \\
17\end{array}$ & $\begin{array}{l}32 \\
22 \\
52\end{array}$ & $\begin{array}{l}0.63 \\
0.41 \\
0.43 \\
p=0.008\end{array}$ & $\begin{array}{l}0.91 \\
0.68 \\
0.67 \\
p=0.01\end{array}$ & $\begin{array}{l}0.34 \\
0.14 \\
0.19 \\
p=0.05\end{array}$ \\
\hline
\end{tabular}

Linear trend (Mantel extension) analysis uses AB DESRD $\leq 50$ as the comparison group.

and DQ4 antigens. While the frequency of the DR4 antigen was high in all $\mathrm{AB}$ groups, the frequency of the DR3 antigen was very low. When detected in diabetic subjects, the DQ4 antigen was always present with DR8. Ninetyone percent of younger AB DESRD subjects had either a DR4 or DR 8 antigen (or both). This frequency was much higher than that observed in older AB DESRD subjects $(68 \% ; p=0.07)$, and was significantly higher than that observed in $\mathrm{AB}$ non-DESRD subjects $(67 \% ; \mathrm{p}=0.03)$.

Table 3 shows the frequency of alleles, phenotypes and presumed homozygosity for HLA A2, DR4, DR8 and combined DR4/DR8 antigens in AB subjects. The frequencies of these parameters for each HLA antigen were highest in $\mathrm{AB}$ DESRD subjects $\leq 50$ years. The $\chi^{2}$ for linear trend was significant when comparing most A2, DR8, and DR4/DR8 frequencies between the three groups. As noted above, $91 \%$ of AB DESRD subjects $\leq 50$ years had either a DR4 or DR8 antigen, and 1/3 appeared homozygous for one or the other.

Table 4 shows the frequencies of combinations of A2, DR 4 and DR8 antigens within the AB groups. Over 65\% of younger AB DESRD subjects had either an A2/DR4 or A2/DR8 haplotype (OR 5.09 [CI 1.35, 20.15] when compared to older AB DESRD subjects, and OR 3.32 [CI $1.20,9.3]$ when compared to $\mathrm{AB}$ non-DESRD subjects). Over $40 \%$ of $\mathrm{AB}$ DESRD $\leq 50$ subjects were homozygous for at least one of the A2, DR4 or DR8 antigens. Using pairwise comparisons, the corresponding frequencies in older AB DESRD and AB non-DESRD subjects were significantly lower. The differences in all comparisons were also significant using $\chi^{2}$ for linear trend. Fewer than $10 \%$ (three) of AB DESRD $\leq 50$ subjects had no DR 4 or DR8 antigen compared to $31.8 \%$ of older $\mathrm{AB}$ DESRD subjects and $32.7 \%$ of $\mathrm{AB}$ non-DESRD subjects. These differences were also highly significant.

\section{Discussion}

As far as we are aware, this is the first report of an association between specific HLA antigens and diabetic nephropathy in a Canadian aboriginal population. We have now shown that younger aboriginal people with DESRD have high frequencies of the HLA-A2, HLADR4 and DR8 antigens, compared to older AB DESRD subjects and $\mathrm{AB}$ subjects with non-DESRD. More significantly, AB DESRD $\leq 50$ subjects were over three times as likely to have an HLA-A2/DR4 or HLA-A2/DR8 haplotype than the other two groups. Forty percent were homozygous (or had only one antigen identified) for at least one of A2, DR4 or DR8. We also observed high frequencies of other diabetes-associated HLA antigens 
Table 4. Frequencies of HLA antigen combinations in aboriginal people with renal failure

\begin{tabular}{|c|c|c|c|c|c|c|c|c|c|}
\hline \multirow[t]{2}{*}{ HLA profile } & \multicolumn{2}{|c|}{$\mathrm{AB}$ DESRD $\leq 50$} & \multicolumn{2}{|c|}{$\mathrm{AB}$ DESRD $>50$} & \multicolumn{2}{|c|}{ AB non-DESRD } & \multirow{2}{*}{$\begin{array}{l}\chi^{2} \text { linear } \\
\text { trend }\end{array}$} & \multirow{2}{*}{$\begin{array}{l}\text { AB DESRD } \leq 50 \text { vs. } \\
\text { AB DESRD }>50 \\
\text { OR }(C I)\end{array}$} & \multirow{2}{*}{$\begin{array}{l}\text { AB DESRD } \leq 50 \text { vs. } \\
\text { AB non-DESRD } \\
\text { OR (CI) }\end{array}$} \\
\hline & $\%$ & $\mathrm{n}$ & $\%$ & $\mathrm{n}$ & $\%$ & $\mathrm{n}$ & & & \\
\hline $\mathrm{A} 2 / 2$ and $\mathrm{DR} 4 / 4$ or $\mathrm{DR} 8 / 8$ & 9.4 & 3 & 4.5 & 1 & 3.9 & 2 & & & \\
\hline $\mathrm{A} 2 / \mathrm{X}$ and $\mathrm{DR} 4 / 4$ or $\mathrm{DR} 8 / 8$ & 18.8 & 6 & 4.5 & 1 & 5.8 & 3 & & & \\
\hline $\mathrm{A} 2 / 2$ and one DR4 or DR8 & 12.5 & 4 & 0 & 0 & 3.9 & 2 & & & \\
\hline $\mathrm{A} 2 / \mathrm{X}$ and $\mathrm{DR} 4 / \mathrm{X}$ or DR8/X & 25.0 & 8 & 18.2 & 4 & 23.1 & 12 & & & \\
\hline Total of above & 65.5 & 21 & 27.3 & 6 & 36.5 & 19 & 0.002 & $5.09(1.35,20.15)^{b}$ & $3.32(1.20,9.30)^{\mathrm{a}}$ \\
\hline One or more homozygous & 40.6 & 13 & 9.1 & 2 & 13.5 & 7 & 0.0009 & $6.84(1.24,68.18)^{\mathrm{a}}$ & $4.40(1.36,14.67)^{b}$ \\
\hline $\mathrm{AX} / \mathrm{X}$ and $\mathrm{DR} 4 / 4$ or DR8/8 & 6.3 & 2 & 4.5 & 1 & 9.6 & 5 & & & \\
\hline $\mathrm{AX} / \mathrm{X}$ and $\mathrm{DR} 4 / \mathrm{X}$ or DR8/X & 18.8 & 6 & 36.4 & 8 & 21.2 & 11 & & & \\
\hline Total previous 2 & 25.0 & 8 & 40.9 & 9 & 30.8 & 16 & n.s. & $0.48(0.13,1.79)$ & $0.75(0.25,2.24)$ \\
\hline $\mathrm{A} 2 / 2$ and no DR4 or DR8 & 0 & 0 & 0 & 0 & 3.9 & 2 & & & \\
\hline $\mathrm{A} 2 / \mathrm{X}$ and no DR 4 or DR 8 & 3.1 & 1 & 9.1 & 2 & 17.3 & 9 & & & \\
\hline No A2, DR4 or DR8 & 6.3 & 2 & 22.7 & 5 & 11.5 & 6 & & & \\
\hline Total previous 3 & 9.4 & 3 & 31.8 & 7 & 32.7 & 17 & 0.01 & $0.15(0.02,0.75)^{b}$ & $0.21(0.04,0.86)^{\mathrm{a}}$ \\
\hline Total number of subjects & 100 & 32 & 100 & 22 & 100 & 52 & & & \\
\hline
\end{tabular}

${ }^{\mathrm{a}} \mathrm{p}<0.05 ;{ }^{\mathrm{b}} \mathrm{p} \leq 0.01$.

Linear trend (Mantel extension) analysis uses AB DESRD $\leq 50$ as the comparison group.

(A24, B62, DQ3, and DQ4) in the AB groups (see below), but differences between subgroups were not statistically significant.

We believe that our findings are compatible with the hypothesis that $\mathrm{AB}$ subjects with $\mathrm{T} 2 \mathrm{DM}$ who are younger at the time of DESRD diagnosis, are more likely to have an HLA-associated genetic propensity for the disease. The fact that $\mathrm{AB}$ non-DESRD subjects had somewhat higher frequencies of HLA-A2 and DR4 (and the corresponding haplotype) than older AB DESRD subjects is likely explained by the younger age of the former. Consequently, they may still have been at risk of developing T2DM (and its complications) when they started ESRD treatment for causes of renal failure other than diabetes. Another possibility is that the HLA-A2/DR4 haplotype may predispose to $\mathrm{AB}$ renal failure regardless of etiology.

Our results are consistent with an earlier study in the Pima that showed an inverse relationship between HLAA2 allele frequency and age of individuals with T2DM [10]. In contrast to findings in the Pima, however, Saskatchewan aboriginal subjects are from diverse origins including Cree, Dene, Saulteaux and Sioux First Nations, as well as a mixed Caucasian/aboriginal heritage (Metis). It is possible that there may be further HLA differences within these subpopulations, but we were unable to accurately determine the precise origins of our subjects, and small numbers would likely have prevented us from carrying out subgroup analysis.

It is not clear from our study whether the associations that we have identified are between specific HLA antigens and DESRD, or between HLA antigens and T2DM. Either or both explanations are possible. The HLA antigens A2 [11], A24 [12-16], DR4 [9], DR8 [17-19], DQ4 [2022], and DQ3-related alleles [23, 24] have all been linked to T1DM. Additionally, high frequencies of HLA A2 [10, 25], DR4 [25-27] and DQ7 [28] have been found in some populations with T2DM. HLA-A2 has also been associated with microalbuminuria in people with T1DM [29], and with mortality from cardiovascular disease in Pima Indians [30]. Finally, an increased occurrence of HLAB62 has been reported in Blacks with T1DM and DESRD [31]. We expected and observed higher frequencies of some of these antigens (particularly HLA-DR4 and DR3) in non-AB DESRD subjects compared to non-AB with non-DESRD, because the former included large numbers of people with T1DM. Interestingly, both AB DESRD and $\mathrm{AB}$ non-DESRD groups in our study had higher frequencies of DR4 than the non-AB DESRD group, but had very low frequencies of DR3.

There are several limitations to this retrospective study. First, numbers were small and we particularly lacked HLA data for many older AB subjects with 
DESRD. Second, our use of age at DESRD diagnosis to differentiate between younger and older AB DESRD subjects might not accurately parallel age of diagnosis of diabetic nephropathy. Third, we cannot be sure that identification of only a single HLA-A, -B or -DR antigen meant that an individual subject was homozygous for that allele; however, that does not affect the main findings of the study. Fourth, there may have been some misclassification of subjects by ethnicity and DESRD diagnosis, but that would tend to make our findings more conservative, rather than lead to a type 1 error. Finally, we were unable to compare HLA frequencies in our AB DESRD subjects with an optimal $\mathrm{AB}$ control population such as matched healthy subjects without a high risk for T2DM and renal disease; however, identifying such individuals might be very difficult. The fact that other North American Indian populations are also known to have high frequencies of A2, A24, DR4 and DR8 [32, 33] lends support to the sobering possibility that large proportions of these populations may have a genetic propensity to develop T2DM and its complications.

This preliminary report requires verification through larger studies that use more sophisticated genetic studies that were not available during the early part of our study period. Such investigations within native North American populations are beginning to emerge. For example, Mexican patients with T2DM have been shown to be eight times as likely to develop DESRD if they had the HLA class II gene DRB1*1502 (an HLA-DR2 allele) [34]. Segregation analysis carried out in the Pima also suggests a major gene effect contributing to diabetic nephropathy [35]; linkage analysis indicates that candidate genes may be on chromosome $7[36,37]$.
This report adds to the increasing evidence that T2DM and its complications have a defined genetic basis in aboriginal populations, and that the observed HLA associations have much in common with those reported in T1DM. Although a genetic susceptibility to diabetic nephropathy (and T2DM) in North American aboriginal peoples may partially explain the burgeoning rates of DESRD in these populations, it is important to put this in perspective. T2DM was distinctly uncommon if not absent in these populations prior to the middle of the last century [38]. It is therefore clear that environmental factors are responsible for the appearance of T2DM and T2DM complications that are ravaging indigenous peoples worldwide. Identifying and understanding the genetics of T2DM should therefore be seen as a reason for hope. In immediate terms, it can provide us with an opportunity to screen for high-risk individuals who may benefit from prevention strategies, or early diagnosis and treatment. If confirmed, our findings should also give reason for caution in recommending aboriginal persons with high risk HLA profiles for kidney donation. In the more distant future, there may be opportunities to prevent or cure T2DM and its complications by targeting the genetic basis for this disease.

\section{Acknowledgements}

We wish to thank our nephrology colleagues in Saskatchewan for allowing us access to data from their ESRD patients. We also thank the Canadian Organ Replacement Registry for retrieving the Saskatchewan data used in this study.

\section{References}

1 Dyck RF: Mechanisms of renal disease in indigenous populations: Influences at work in Canadian indigenous peoples. Nephrology 2001;6:3-7.

2 Young TK, Reading J, Elias B, O'Neil JD: Type 2 diabetes mellitus in Canada's First $\mathrm{Na}$ tions: Status of an epidemic in progress. Can Med Assoc J 2000;163:561-566.

3 Dyck RF, Tan L: Rates and outcomes of diabetic end-stage renal disease among registered native people in Saskatchewan. Can Med Assoc J 1994;150:203-208.

4 Nelson RG: Diabetic renal disease in transitional and disadvantaged populations. Nephrology 2001;6:9-17.
5 Pettitt DJ, Saad MF, Bennett PH, Nelson RG, Knowler WC: Familial predisposition to renal disease in two generations of Pima Indians with type 2 (non-insulin-dependent) diabetes mellitus. Diabetologia 1990;33:438-443.

6 Freedman BI, Spray BJ, Tuttle AB, Buckalew VM: The familial risk of end-stage renal disease in African-Americans. Am J Kidney Dis 1993; 21:387-393.

7 Faronato PP, Maioli M, Tonolo G, Brocco E, Noventa F, Piarulli F, Abaterusso C, Modena $\mathrm{F}$, de-Bigontina $\mathrm{G}$, Velussi $\mathrm{M}$, Inchiostro $\mathrm{S}$, Santeusanio F, Bueti A, Nosadini R: Clustering of albumin excretion rate abnormalities in Caucasian patients with NIDDM. Diabetologia 1997;40:816-823.
8 Canani LH, Gerchman F, Gross JL: Familial clustering of diabetic nephropathy in Brazilian type 2 diabetic patients. Diabetes 1999;48: 909-913.

9 Field LL, Tobias R: Unravelling a complex trait: the genetics of insulin-dependent diabetes mellitus. Clin Invest Med 1997;20:41-49.

10 Williams RC, Knowler WC, Butler WJ, Pettitt DJ, Lisse JR, Bennett PH, Mann DL, Johnson AH, Terasaki PI: HLA-A2 and type 2 (insulin independent) diabetes mellitus in Pima Indians: An association of allele frequency with age. Diabetologia 1981;21:460-463. 
11 Fennessy M, Metcalfe K, Hitman GA, Niven M, Biro PA, Tuomilehto J, Tuomilehto-Wolf E: A gene in the HLA class I region contributes to susceptibility to IDDM in the Finnish population: Childhood diabetes in Finland (DiMe) study group. Diabetologia 1994;37:937-944.

12 Honeyman MC, Harrison LC, Drummond B, Colman PG, Tait BD: Analysis of families at risk for insulin-dependent diabetes mellitus reveals that HLA antigens influence progression to clinical disease. Mol Med 1995;1:576-582.

13 Langholz B, Tuomilehto-Wolf E, Thomas D, Pitkaniemi J, Tuomilehto J: Variation in HLAassociated risks of childhood insulin-dependent diabetes in the Finnish population. I. Allele effects at A, B, and DR loci. DiMe Study Group. Childhood diabetes in Finland. Genet Epidemiol 1995;12:441-453.

14 Adamashvili I, McVie R, Gelder F, Gautreaux M, Jaramillo J, Roggero T, McDonald J: Soluble HLA class I antigens in patients with type I diabetes and their family members. Hum Immunol 1997;55:176-183.

15 Nakanishi K, Kobayashi T, Inoko H, Tsuji K, Murase T, Kosaka K: Residual beta-cell function and HLA-A24 in IDDM: Markers of glycemic control and subsequent development of diabetic retinopathy. Diabetes 1995;44:13341339.

16 Nakanishi K, Kobayashi T, Murase T, Nakatsuji $\mathrm{T}$, Inoko $\mathrm{H}$, Tsuji K, Kosaka K: Association of HLA-A24 with complete beta-cell destruction in IDDM. Diabetes 1993;42:10861093.

17 Noble JA, Valdes AM, Cook M, Klitz W, Thomson G, Erlich HA: The role of HLA class II genes in insulin-dependent diabetes mellitus: Molecular analysis of 180 Caucasian, multiplex families. Am J Hum Genet 1996;59:11341148 .

18 Thomson G: HLA DR antigens and susceptibility to insulin-dependent diabetes mellitus. Am J Hum Genet 1984;36:1309-1317.

19 Dubois-Laforgue D, Timsit J, Djilali-Saiah I, Boitard C, Caillat-Zucman S: Insulin-dependent diabetes mellitus in non-DR3/non-DR4 subjects. Hum Immunol 1997;57:104-109.
20 Ronningen KS, Gjertsen HA, Iwe T, Spurkland A, Hansen T, Thorsby E: Particular HLA-DQ alpha beta heterodimer associated with IDDM susceptibility in both DR4-DQw4 Japanese and DR4-DQw8/DRw8-DQw4 whites. Diabetes 1991;40:759-763.

21 Sugihara S, Sakamaki T, Konda S, Murata A, Wataki K, Kobayashi Y, Minamitani K, Miyamoto S, Sasaki N, Niimi H: Association of HLA-DR, DQ genotype with different beta-cell functions at IDDM diagnosis in Japanese children. Diabetes 1997;46:1893-1897.

22 Ronningen KS, Keiding N, Green A: Correlations between the incidence of childhood-onset type I diabetes in Europe and HLA genotypes. Diabetologia 2001;44:B51-59.

23 Sheehy MJ, Scharf SJ, Rowe JR, Neme-deGimenez MH, Meske LM, Erlich HA, Nepom BS: A diabetes-susceptible HLA haplotype is best defined by a combination of HLA-DR and -DQ alleles. J Clin Invest 1989;83:830-835.

24 Baisch JM, Weeks T, Giles R, Hoover M, Stastny P, Capra JD: Analysis of HLA-DQ genotypes and susceptibility in insulin-dependent diabetes mellitus. N Engl J Med 1990;322: 1836-1841.

25 Tuomilehto-Wolf E, Tuomilehto J, Hitman GA, Nissinen A, Stengard J, Pekkanen J, Kivinen P, Kaarsalo E, Karvonen MJ: Genetic susceptibility to non-insulin dependent diabetes mellitus and glucose intolerance are located in HLA region. BMJ 1993;307:155-159.

26 Rich SS, Panter SS, Goetz FC, Hedlund B, Barbosa J: Shared genetic susceptibility of type 1 (insulin-dependent) and type 2 (non-insulindependent) diabetes mellitus: Contributions of HLA and haptoglobin. Diabetologia 1991;34: 350-355.

27 Rich SS, French LR, Sprafka JM, Clements JP, Goetz FC: HLA-associated susceptibility to type 2 (non-insulin-dependent) diabetes mellitus: The Wadena City Health Study. Diabetologia 1993;36:234-238.

28 Banerji MA, Norin AJ, Chaiken RL, Lebovitz HE: HLA-DQ associations distinguish insulinresistant and insulin-sensitive variants of NIDDM in black Americans. Diabetes Care 1993;16:429-433.

29 Watts GF, Taub N, Gant V, Wilson I, Shaw KM: The immunogenetics of early nephropathy in insulin-dependent diabetes mellitus: Association between the HLA-A2 antigen and albuminuria. Q J Med 1992;83:461-471.
30 Williams RC, Hanson RL, Pettitt DJ, Sievers ML, Nelson RG, Knowler WC: HLA *A2 confers mortality risk for cardiovascular disease in Pimans. Tissue Antigens 1996;47:188-193.

31 Freedman BI, Espeland MA, Heise ER, Evans $\mathrm{J}$, Canzanello VJ: Racial variation in human leukocyte antigen frequency in insulin-dependent diabetic nephropathy. J Am Soc Nephrol 1993;3:1467-1473.

32 Lee TD, Zhao TM, Chow MP, Lee G: HLA, GM, KM, and Diego blood group typing of Chippewa Indians. Transfusion 1990;30:728732.

33 Stroncek DF, Strand RD, Noreen HJ, Kline WE, McGlave PB, Bartsch GE, McCullough J: HLA class I and II antigen phenotypes of North American Indians from Minnesota: Implications for marrow transplants using unrelated donors. Transfusion 1990;30:521-527.

34 Perez-Luque E, Malacara JM, Olivo-Diaz A, Alaez C, Debaz H, Vazquez-Garcia M, Garay ME, Nava LE, Burguete A, Gorodezky C: Contribution of HLA class II genes to end stage renal disease in Mexican patients with type 2 diabetes mellitus. Hum Immunol 2000;61: 1031-1038.

35 Imperatore G, Knowler WC, Pettitt DJ, Kobes S, Bennett PH, Hanson RL: Segregation analysis of diabetic nephropathy in Pima Indians. Diabetes 2000;49:1049-1056.

36 Imperatore G, Hanson RL, Pettitt DJ, Kobes S, Bennett PH, Knowler WC: Sib-pair linkage analysis for susceptibility genes for microvascular complications among Pima Indians with type 2 diabetes. Diabetes 1998;47:821-830.

37 Hanson RL, Ehm MG, Pettitt DJ, Prochazka M, Thompson DB, Timberlake D, Foroud T, Kobes S, Baier L, Burns DK, Almasy L, Blangero J, Garvey WT, Bennett PH, Knowler WC: An autosomal genomic scan for loci linked to type II diabetes mellitus and body-mass index in Pima Indians. Am J Hum Genet 1998;63: 1130-1138.

38 Chase LA: The trend of diabetes in Saskatchewan, 1905-34. Can Med Assoc J 1937;36:366369. 